\title{
Teachers Storying Themselves Into Teaching: Comics as an Emergent and Relational Form of Research
}

\author{
Natalie LeBlanc and Rita L. Irwin
}

\begin{abstract}
In this article, we explore two comics that were produced in a province-wide teacher mentorship initiative in British Columbia, Canada. Comics-based research, undertaken through a collaborative approach, underscores the potential for this kind of research to highlight teacher stories and methodologically engage in an artistic collaboration within a research team. We use this opportunity to discuss how the mentoring project brought to our awareness the importance of sharing teachers' stories among peers, as teachers came together to study their professional practices.
\end{abstract}

\section{Situating the Inquiry}

We consider teacher mentorship as an interdependent and collaborative relationship in which teachers learn together to inquire and refine their practice. Our research project contributes to the scholarship on teacher mentoring programs by facilitating dialogue across educational communities, developing educational resources, and creating opportunities for coalitions and research collaborations.

Teacher mentorship matters because research consistently shows that teacher quality is the most important school-related determinant of student success (Ingersoll \& Strong, 2011; Kutsyuruba, 2012; Moir, 2009). Such evidence has led many educational authorities worldwide to invest in teacher mentoring programs as a powerful tool for closing the teacher quality gap (Kent, Feldman, \& Hayes, 2009). Positive impacts of such programs include accelerating new teacher growth, improving student learning, and increasing the quality of teaching (Feiman-Nemser, 2012; Karsenti \& Collin, 2013). Without high-quality teacher mentorship, efforts to improve teacher quality are often prevented by the high rates of turnover. The consequences of high teacher turnover rates are diminished school capacity, attrition of competent teachers, loss of education dollars, and most importantly, significant negative impact on student learning outcomes (Kelly, 2004; Hong, 2010).

This paper adds to the larger discussion of the importance of teacher mentorship in early teaching practices by examining how comics-based research, an artful combination of narrative and arts-based educational research, captures personal experiences of beginning teachers as a way of understanding the significance that mentoring has played in their teaching practice. Moreover, in utilizing comics, our research deepens understandings of teacher mentorship, while provoking relational modes of engagement between the researchers involved in the process of data collection, comic-making, and between the scholarly and educational community. 


\section{Methodology}

For our research, we adopted a collaborative arts-based methodology as a platform for telling, reflecting upon, and sharing stories (Leavy, 2009). Using a multi-method approach to research, we included ethnographic methods as well as semi-structured interviews with open-ended questions. Our process involved gathering data from participants through conducting video-recorded interviews with teachers, learning assistant teachers, and administrators who were involved in the selected school districts' mentoring programs and initiatives in British Columbia, Canada. Each research participant was interviewed at least twice over the duration of a year to learn more about their experiences as a mentor, a mentee, or a mentoring coordinator.

We used video to study the character, strengths, and uniqueness of selected districts' mentoring programs. ${ }^{1}$ During the interviews, however, there was an interesting turn of events. After a request for anonymity was made by one of the participating teachers, the form of comics was introduced as an alternative image-based research output. As such, the comic form facilitated anonymity by masking participants' identities, which coincided with the ability of one of our team members who is a professional cartoonist and educator and well versed in the language of comic books in the educational landscape (Lawrence, Lin, \& Irwin, 2017; Lin, Lawrence, \& Irwin, 2016; Irwin, Lin, \& Lawrence, 2015).

For this paper, we examine the artistic and collaborative process that comics afforded the research team, which we have come to perceive as an artistic hybrid of narrative and arts-based methodologies. Six four-to-five-page researcher-produced comics were created as part of our research project (see Fig. 1). This paper presents two comics that were produced for beginning teachers living and working in remote rural areas of British Columbia, Canada. A portion of this paper focuses on the production of these two comics, exploring how they have created a platform for storying the experiences of beginning teachers, while also offering a new way of sharing these stories with/in a larger network of educators in the province.

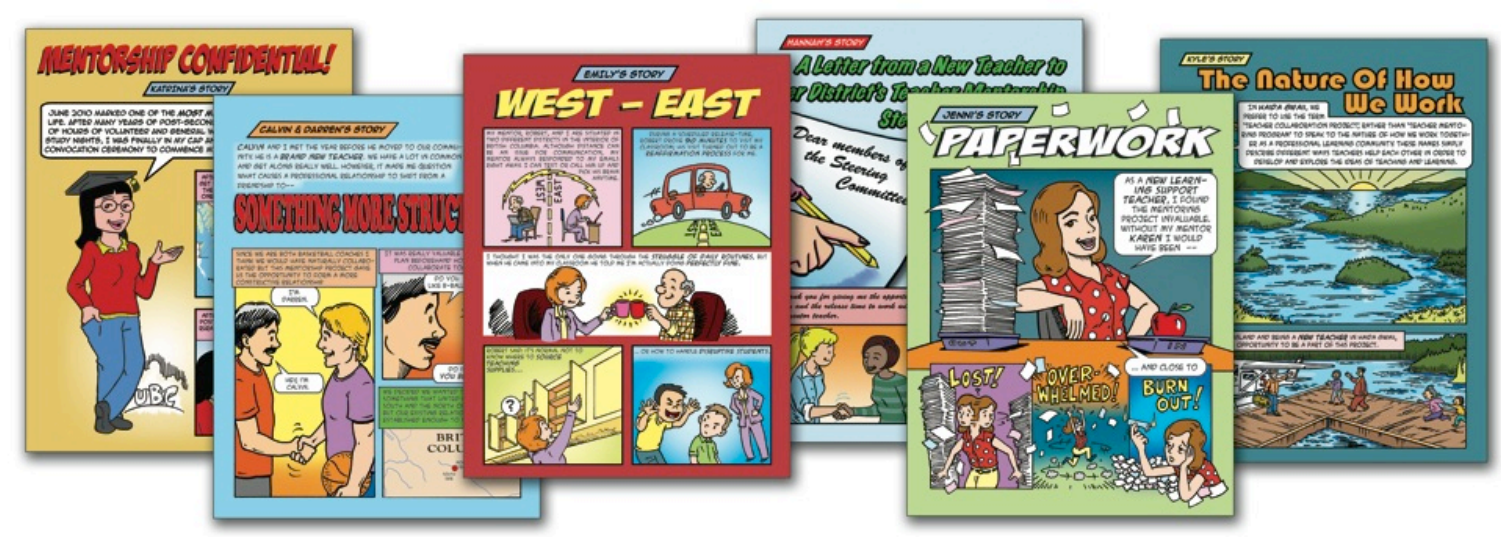

Fig. 1: Six comics were created as part of this research project. The comics, as an assemblage of multiple teaching experiences, capture the complexity of the teaching profession and the need for teacher mentorship, providing opportunities for closer interpersonal and cross-provincial relationships. Digital versions can be accessed from our research website:

http://mentoringbc.edcp.educ.ubc.ca/research/comics/ 
Teachers Storying Themselves Into Teaching: Comics as an Emergent and Relational Form of Research

For the purposes of this paper, interviews were conducted with the research team that includes the interviewer who spoke with the practitioners on-site, research associate Dr. Ching-Chiu Lin, as well as the transcriber of these interviews, research assistant Amber Lum, and the comic-creator, Julian Lawrence. Finally, we consider several reactions within the mentoring project participants, in which we articulate towards the end of this paper as post-comic dialogues.

\section{Comics: A Spatial and Relational Way of Telling Stories}

The research team has come to perceive comics as an artistic and aesthetic form of storytelling. Connelly and Clandinin (1990) have long argued for the need of narrative inquiry in studies concerning educational experience, positing that, "humans are storytelling organisms who, individually and socially, lead storied lives" (p. 2). For this project, the research team engaged in a collaborative methodology that combined traditional qualitative practices such as ethnographic observations and various forms of interviews, with more emergent and innovative arts-based approaches. By attending to the personal and to the social qualities of the participants' stories about their mentoring experiences, we selected an approach that could attend to the complexities pertaining to the relationships between teaching and learning, researching and teaching, and the multiple roles that the researchers played in the comicmaking process.

Under the larger umbrella of Narrative Inquiry reside many arts-based methodological practices. Patricia Leavy (2009) argues,

Narrative inquiry attempts to collaboratively access participants' life experiences and engage in a process of storying and restorying in order to reveal multidimensional meanings and present authentic and compelling rendering of data. In other words, narratives are constructed out of data through a reflexive, participatory, and aesthetic process (pp. 27-28).

To a certain extent, the comics created in this research project explore the potential of narrative inquiry (Connelly \& Clandinin, 1990) by attending to the narrative nature of the beginning teachers' mentoring experience. However, they share commonalities in form and in purpose, with a mode of social inquiry that has recently emerged as comics-based research (CBR). Gaining popularity in arts-based educational discourses (Jones \& Woglom, 2013a; Sousanis, 2017), CBR is described as "a broad set of practices that use the comics form to collect, analyze, and/or disseminate scholarly research" (Kuttner, Sousanis, \& Weaver-Hightower, 2017, p. 397). It is a flexible and multimodal form of research that explores and analyzes research participants' stories and it is also a powerful means of representing research findings.

Jeff Adams (2001) investigated the potential of comics in a critical study to construct student-teacher narratives through experimentations with graphic novels and found that comics can be a provocative form of social realism. The medium of comics allowed Adams' student-teachers to pursue serious social issues in which they were afforded a wide variety of styles and aesthetics, which provided the opportunity to experiment with various pictorial devices and compositional elements. Through the use of sequence, repetition, and juxtaposition, the medium of comics allowed students a large amount of freedom in the selection and combination of visual and textual forms to depict their stories.

LEARNing Landscapes | Spring 2018, Vol. 11 No. 2 | 225 
Visual arts-based researcher, Marta Madrid-Manrique (2014), argues that comics are capable of showing things that cannot be shown otherwise. Through metaphor, Madrid-Manrique creates a visual language capable of conveying affect and complex emotions. Take for instance the use of the gutter, one of comics' key elements in which she refers to as "the in-between space among comic units or strips, which gives the reader the opportunity to interpret the rhythm and relation of scenes, actions, and ideas" (p. 34). Adams (2001) echoes this sentiment by commenting on the evocative power of the transitions between the comic's frames, which in his opinion, "encourages the use of speculation and imagination on the part of the reader/spectator" (p. 134).

Elaborating on his use of comics in his dissertation entitled Unflattening, Nick Sousanis (2015) describes how comics are well suited for telling evocative stories. For Sousanis, comics have a unique capacity for holding visual and verbal modes together in a single form. Furthermore, the "architectonics" (Spiegelman cited by Sousanis, 2015), or the structure in which multiple panels are organized on a single page, produces a spatial interplay that is unique to the graphic form.

For Madrid-Manrique (2014), the process of telling stories through comics is "a creative game" (p. 28), affording researchers a way to solve several problems such as confidentiality and anonymity, while challenging the researcher to (re)consider both reality and fiction on a regular basis. In her opinion, comics

are a narrative language built on visual literacy, hypertextuality and intertextuality. Through the relationship between text and language, they frequently utilize symbolic representations, metaphor, allegory, and other literary [figures] as a way [of] telling the story aesthetically (p. 28).

As a form of relational research, Madrid-Manrique (2014) emphasizes how comics allows for re-presentation and re-telling of difficult experiences such as loss and vulnerability. Rather than drawing on visual modes of representation as a complement to qualitative research, she uses comics as an evocative form of arts-based research to denote how participants live in relation to others and places her participants (literally and figuratively) in "a net of embodied relations" (p. 37).

Embodied relations are further explored in the comics-based research of Jones and Woglom (2013b), who utilize a feminist lens to explore how "a body-and place-focused pedagogy" (p. 1) could enable teacher education students to recognize how they are "full-bodied and cultural beings" (p. 1). The authors demonstrate how such knowledge can expand perceptions of ourselves and others in place. In their opinion, "the place of learning in teacher education is too frequently positioned as a neutral backdrop upon which the 'real' learning about being an educator occurs" (p. 27). Through comics, they render the body and the body-in-relation-to place as the focal point of the narrative in order to emphasize its importance in teacher education curriculum and pedagogy.

Comics-based researchers are exploring ways in which social, cultural, educational, and pedagogical issues can be told through the medium of comics. Using some of the pictorial devices and visual tropes mentioned above, the research team used biographical components extracted from the ethnographic and interview data to compile a series of six comics. Although the results include 
biographical components of each participant's experience in the mentoring program, artistic liberties were exercised to emphasize the relations that each case brought forth. In the following section, we describe two of the comics produced by Katrina and Kyle, two new teachers in a rural school in British Columbia, Canada. Each story is told through a combination of the participants and their relations to the place where they are teaching, and each is told in a way as to remain authentic to the participant's narrative. The entire comic can be accessed by following the (blue) link provided in each section.
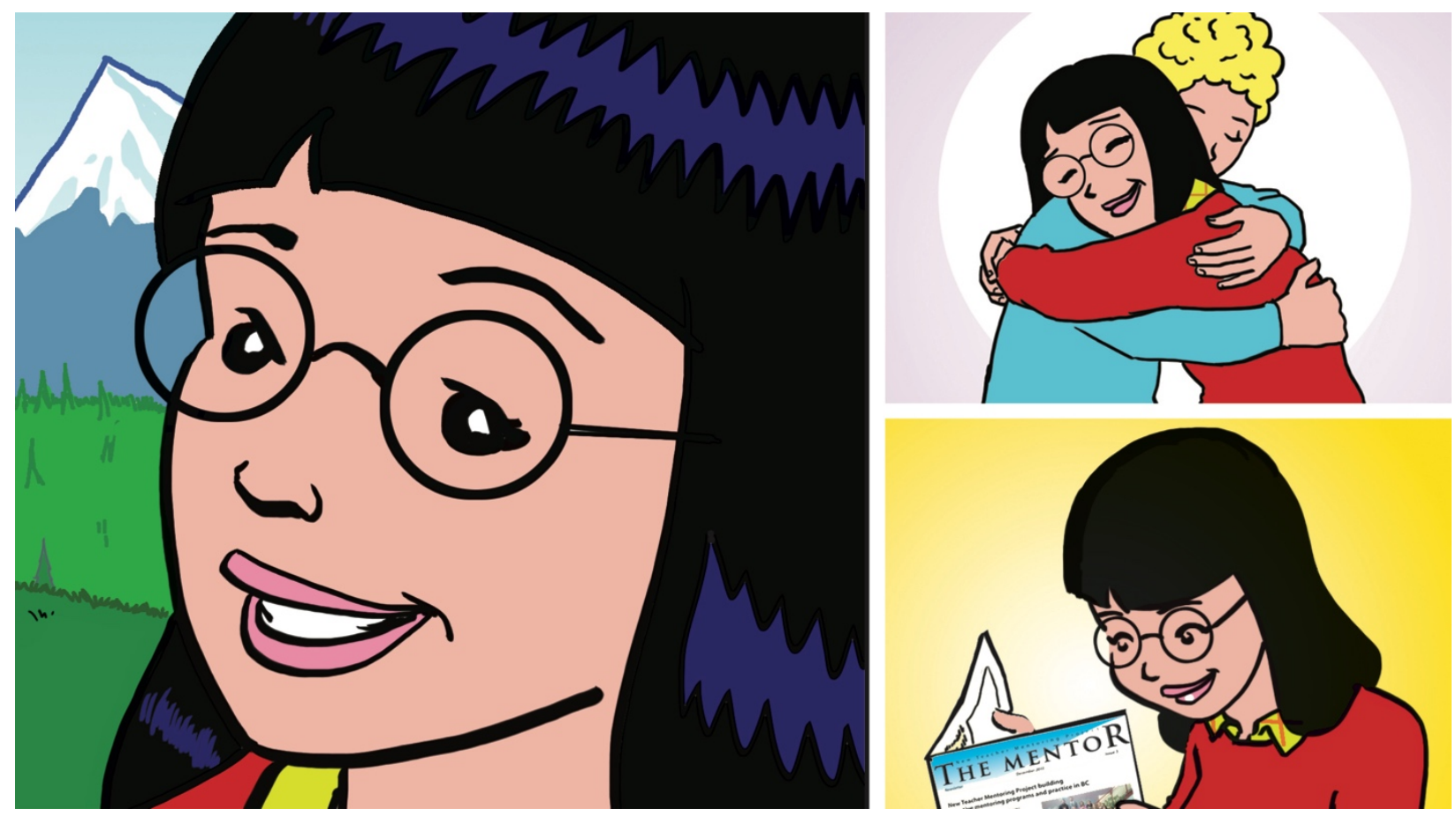

Fig. 2: Select images from "Katrina's Story," a comic produced by the research team. A collaborative endeavor by Ching-Chiu Lin, Julian Lawrence, and Amber Lum. Please see: http://mentoringbc.edcp.educ.ubc.ca/research/comics/.

\section{Comic 1: Katrina's Story}

Katrina's Story depicts the necessity for mentorship programs. The relationship between her and her mentor occurring over a long period of time, emphasizes the roles that observation, reflection, dialogue, and conversation played in her mentoring process.

Commencing her career as an educator in a K-7 one-room school in her "home" school district, Katrina encountered many difficulties that a rural, multi-grade classroom often presents. Within her first four months of working in isolation, she began seeking support. Recalling a guest speaker in her rural education elective at University, she joined the BC Rural and Small Schools PSA (provincial specialist associations), which allowed her to learn about other teachers who were working across the province in similar teaching positions. 
Communicating with these more experienced teachers over the phone, through email, and face-to-face, became an imperative part of Katrina's professional life. These contacts, in combination with funding from her Pro-D chair and the New Teacher Mentoring Project, granted her the opportunity to visit other schools and observe their programs and students. As a result, she learned new and effective strategies for teaching and acquired resources to further help in her teaching practice.

As a platform for raising questions and concerns, the mentoring project expanded Katrina's professional network, allowing her to make meaningful connections with other teachers in similar situations, which helped ease the doubt and uncertainty that she encountered in working in isolation.

In her second year as a participant in the mentorship program, Katrina witnessed a profound impact on her personal and professional growth, which she credits to the project and to her mentor who played such a pivotal role in her professional development. Katrina's Story demonstrates how the mentorship program afforded her the opportunity and time to connect with other teachers, which, in turn, allowed her to expand her professional and social networks. As a result, Katrina, with a desire to grow and improve her teaching practice, received the support that she required in order to do so. Thus, she acquired new skills and confidence, which, as an important form of self-affirmation, helped tremendously, especially in the beginning stage of her career.
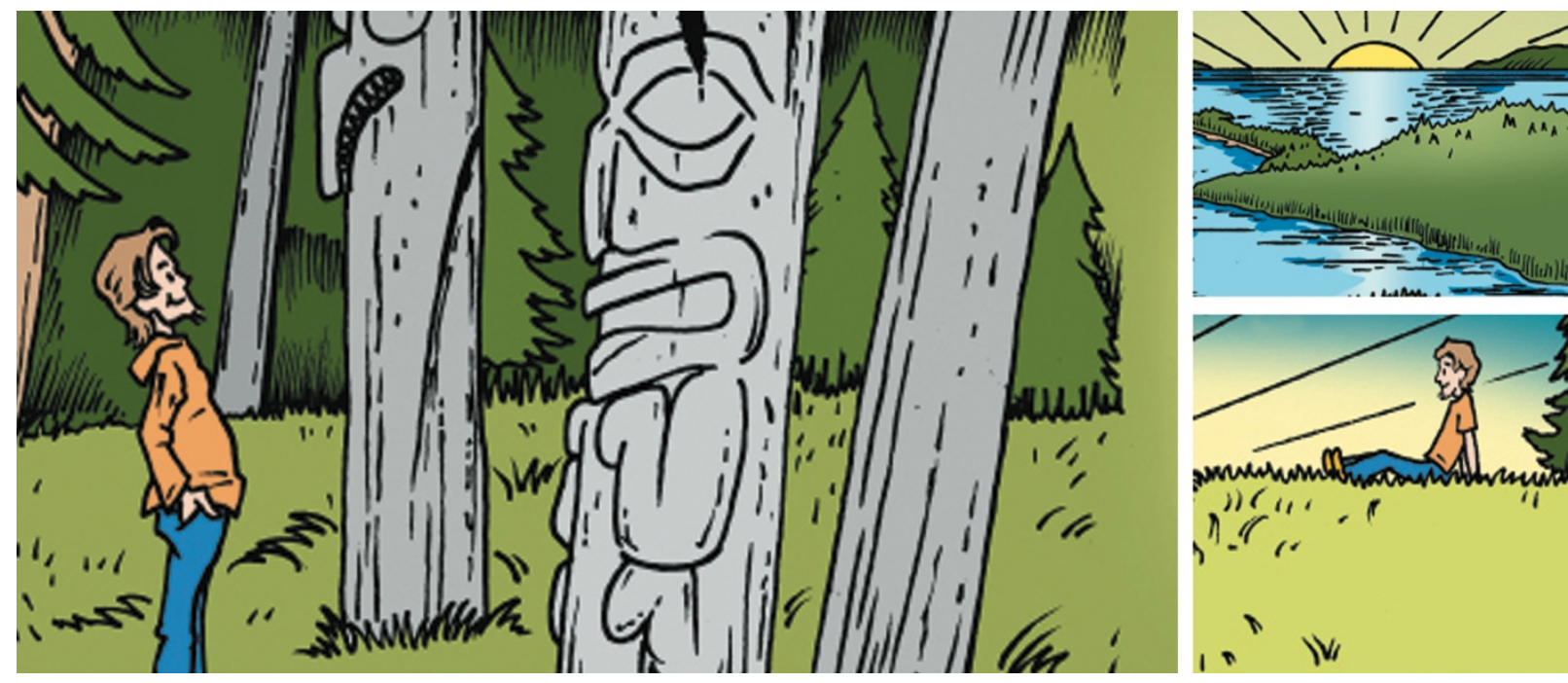

Fig. 3: Select images from "Kyle's Story," a comic produced by the research team. A collaborative endeavor by Ching-Chiu Lin, Julian Lawrence, and Amber Lum. Please see: http://mentoringbc.edcp.educ.ubc.ca/research/comics/.

\section{Comic 2: Kyle's Story}

Kyle's Story is a departure from the other comics created for this project and from the comic produced for Katrina's Story. It is more multilayered, and the images and text are more aesthetically woven together throughout the comic, drawing the reader/viewer into the story by addressing particularities of the area or landscape. 
Kyle's Story depicts a peer collaboration model, whereby teachers form a collaborative partnership or team, so they can learn from one another's varied experience and expertise. The collaborative partners or teams meet on professional development days to design a shared learning focus and receive training to improve collaboration skills. They are intended to provide personal accountability for growth in a specific area of teaching practice and create the conditions for their cultural knowledge and understanding to benefit each other. Peers who are geographically distanced from each other are assisted through the use of technology, establishing a virtual hub through which teachers can connect, and discuss their work.

Both comics reveal how the beginning teachers are deeply committed to their teaching practice. Through their stories, the audience learns the impact that the teacher mentoring project has had on their professional growth. Neither comic discussed is presented as a symmetrical dialogue between the mentor and the mentee. In Katrina's Story, for example, the audience can see the more dominant role that the mentor played in her process by the amount of times that they make an appearance in the comic. In Kyle's Story, however, his own body plays a more central role in the story and in the context of the school and the rural environment in order to emphasize the process of inquiry and reflection, which played the most pivotal role in his professional development.

Although both Katrina and Kyle's stories may appear as a neatly packaged document, the process of arriving there was rather complex and multi-faceted. It was very much a collaborative methodology, relying on both traditional and synergistic research practices. Some of which are outlined in the following section, elaborating on how the comic emerged over time while calling attention to some of the interpretive phases of the research process.

\section{The Collaborative Comic Process}

As a mode of arts-based narrative analysis, the research team extracted themes from the participants' interviews, focusing on their lived experiences, and then re/configured them into a coherent story told through the medium of comics. Using three major parts of the narrative process brought forth by Harvey, Mishler, Koenan, and Harney (2000), and cited by Leavy (2009), we break the comic process down into: 1) Coherence; 2) Turning points, and 3) Replotting or Re-storying.

1. Coherence. Coherence pertains to how the narrative is communicated. It is important to note that during the comic process, participants' interviews are transcribed, and the research team spends a considerable amount of time editing and selecting, or extracting, important events in the narrative to make a coherent story. During this stage, Ching and Amber work on how the story will be told—such as the style, the tense, and the tone. This stage is about honoring what is learned through the interviews, yet, at the same time, creating characters and storylines. As a young adult who avidly reads comics, Amber helps revise the text, making it more readable, fun, and casual. As an academic, Ching's writing can be hard to follow in this format. She has found it very helpful to have Amber's perspective. When this process is complete, Julian, the comic creator, makes small thumbnail sketches and a preliminary storyboard (see Fig. 4). 


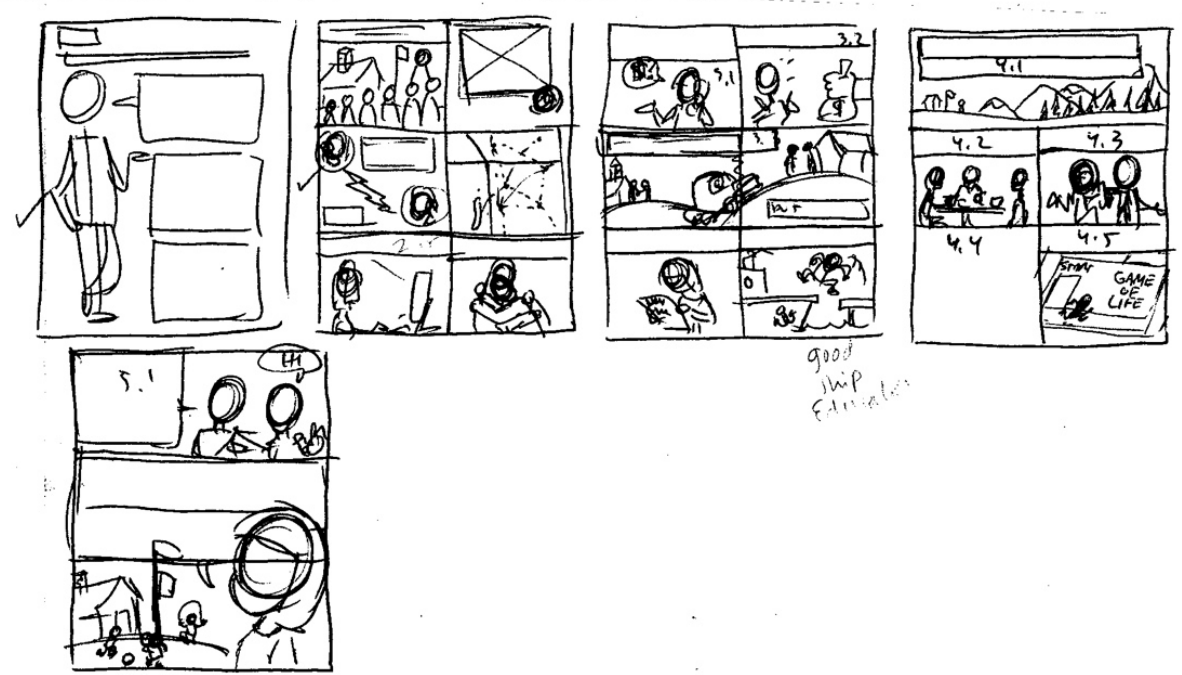

Fig. 4: Small thumbnail sketches produced by Julian Lawrence for "Katrina's Story."

Julian's role in the research is to review the information, in the form of transcripts, audio, and other biographical or autobiographical text sent to him by Ching, and put it together into a cohesive narrative in the form of comics. Working mostly from transcripts of the interviews conducted with teachers and/or their mentors, Julian invents an avatar, an anonymous cartoon-like character to represent the participating teachers. As was the case with Katrina's Story, Julian is rarely provided with any visual cues for what the teachers involved in the research look like. Reading the story presented to him, he imagines their likeness as well as the geographical setting of their teaching. The process involves making artistic decisions and visualizing the teachers' physical features, without seeing any of the images or video interviews, thus maintaining the subjects' anonymity. Although Julian invents an avatar to represent the teacher in the story, he keeps all biographical information (except for the names of the school and the district) true to the story told. This differed only slightly with Kyle's Story, for which Julian was offered a photo reference and used it as a model for his avatar, closely approximating Kyle's likeness to the teacher in the story.

In Katrina's Story, her biographical information was intentionally withheld as she did not want her comic traced back to her identity or district. Her anonymity was protected as Julian had very little knowledge about her identity. Meanwhile, because of the "spatial interplay" afforded to the comic medium, the researchers were able to capture the authenticity of her narrative by including images such as the one-room schoolhouse and the wide, cold landscape.

During the process of reading the transcript, Julian makes edits to keep the story "a more streamlined narrative." He thinks through how the visual can flow better in relation to narrative, whereas, when Ching puts the script together, she does so without having any visuals in mind. At this stage, Julian visualizes what he thinks the teacher should look like, based on impressions that he makes from the words that the teacher uses in the written narrative. From there, he starts developing more concrete physical 
characteristics and begins by drawing simple geometric shapes, ovals for heads, and ovals for body parts, and so forth (see Fig. 5).
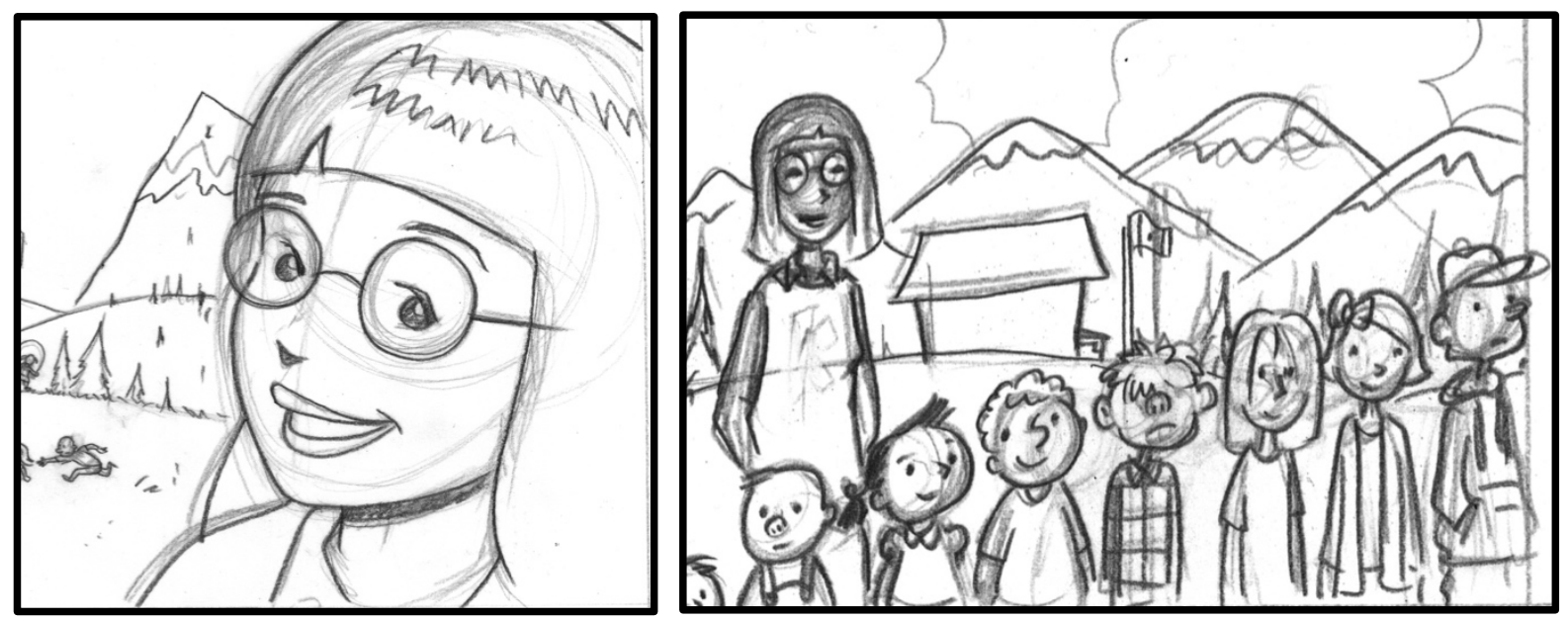

Fig. 5: Avatar sketches produced by Julian Lawrence for "Katrina's Story."

He also tries to visualize the teacher as a character doing activities that are mentioned in the transcript (i.e. sitting behind desks, standing in front of classrooms, driving in their cars, etc.). During the process of roughing out the story, Julian starts refining the look of the character while making important decisions to how the story will be organized. With very small thumbnail sketches, he sequences the panels, and decides on the size and shape of each one to best tell the story. In the margins of his sketches, he often refines the characterization of the main character as well as the secondary characters (such as classroom kids and other faculty). This process most often involves a repetitive process of sketching, erasing, and redrawing, which is sometimes the result of further dialogues with Ching, who is well acquainted with the participant's story. With a background in visual art, Ching often provides input after seeing Julian's initial sketches, sometimes even asking Julian to redraw aspects of the comic again.

Once the roughing out is complete, Julian places in the text using a computer, and by copying and pasting from the transcript. The comic, at this point, is drawn very rough and in pencil, but it is clear enough for everyone involved in the process to read and to see what the final story will look like (see Fig. 6). This version is then sent to Ching who verifies that the elements of the story make sense. After this step, it is sent to the participating teacher for comments or feedback. Once it is approved by the participating teacher, Julian proceeds with the next steps, which involve cleaning up the pencil lines, tracing over them with ink, and applying color. The sense of coherence is accomplished through the collective effort of the team and the participants. 


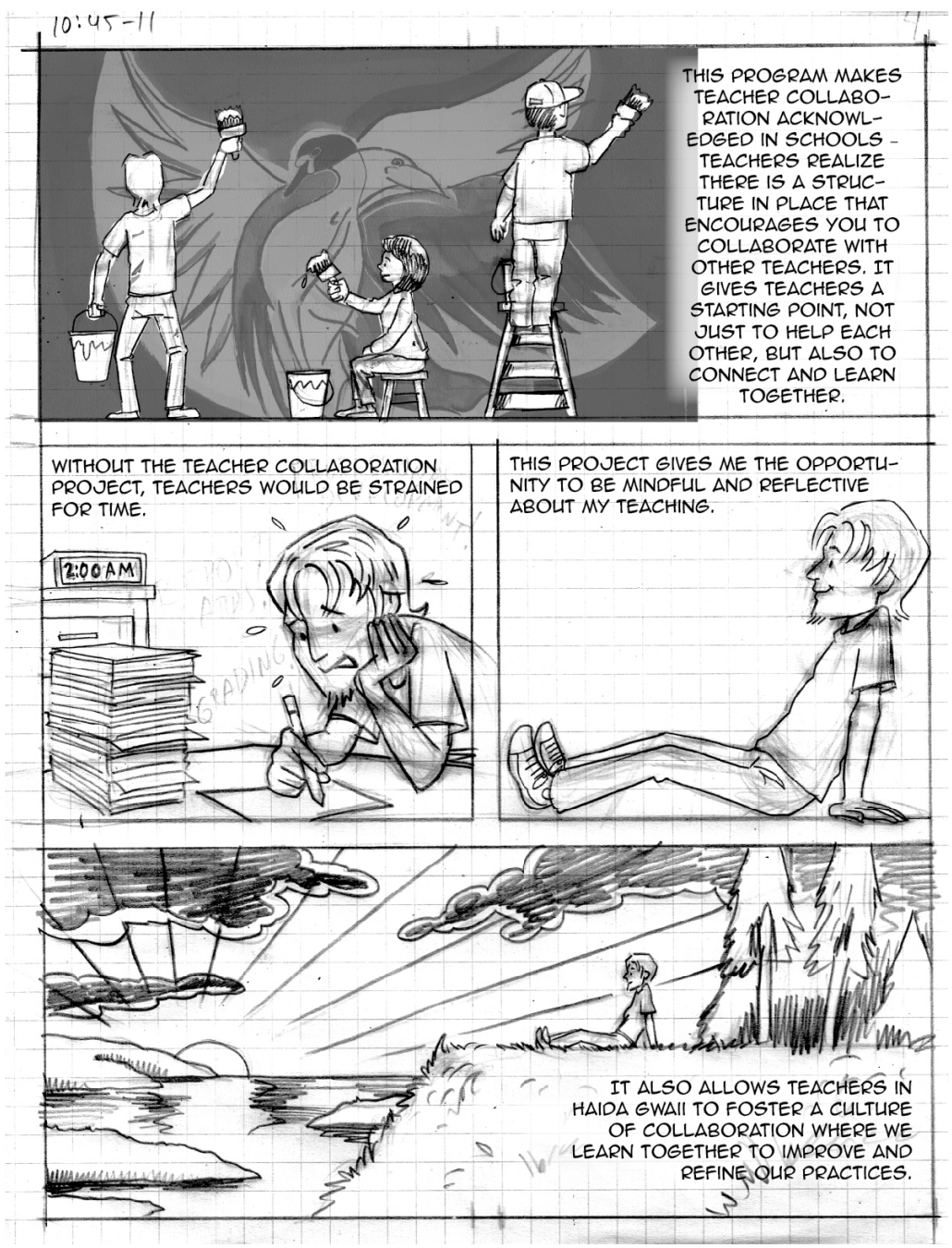

Fig. 6: A combination of hand drawn images with text added with

computer font. Produced by Julian Lawrence for "Kyle's Story."

2. Turning points. Both comics presented in this paper are in the format of a story in which a pivotal point of the narrative signals a shift in experience/interpretation, which Ching, Amber, and Julian all play a role in molding. For example, in Katrina's Story, the turning point is realizing what the mentorship program has afforded her in her professional development and in Kyle's Story, the turning point is how the teacher mentorship project, in a remote indigenous community, takes the shape of peer collaboration, where the needs of students and the community guide his growth as a teacher.

During Julian's process, he looks for opportunities to utilize his artistry as a comics creator to highlight these turning points. For example, in Katrina's Story on page four, the last panel portrays Katrina running on a board game. The text reads, "it is the mentorship program that's afforded me the opportunities to get to this vital point at an early stage in my career." In this instance, Julian interpreted "career" as a board game involving the rolling of dice and the constant feeling of running forward. In this panel, Katrina's career and her life are depicted as a board game that allows the reader/viewer to join in the 
visualization to better understand the importance of the mentorship project on Katrina's life while simultaneously transitioning from one page to the next. In Kyle's Story, Julian used three images, a school garden, a field trip, and salmon smoking process to portray how teachers' peer collaborative activities help nurture teacher mentorship. Standing further apart from all the other comics that were produced, Julian even used some of Kyle's own artwork to highlight the role that the appreciation for the Haida culture played in Kyle's growth as a teacher (see page 3, panel 2 and page 4, panel 1 in Kyle's comic and Fig. 7 below).

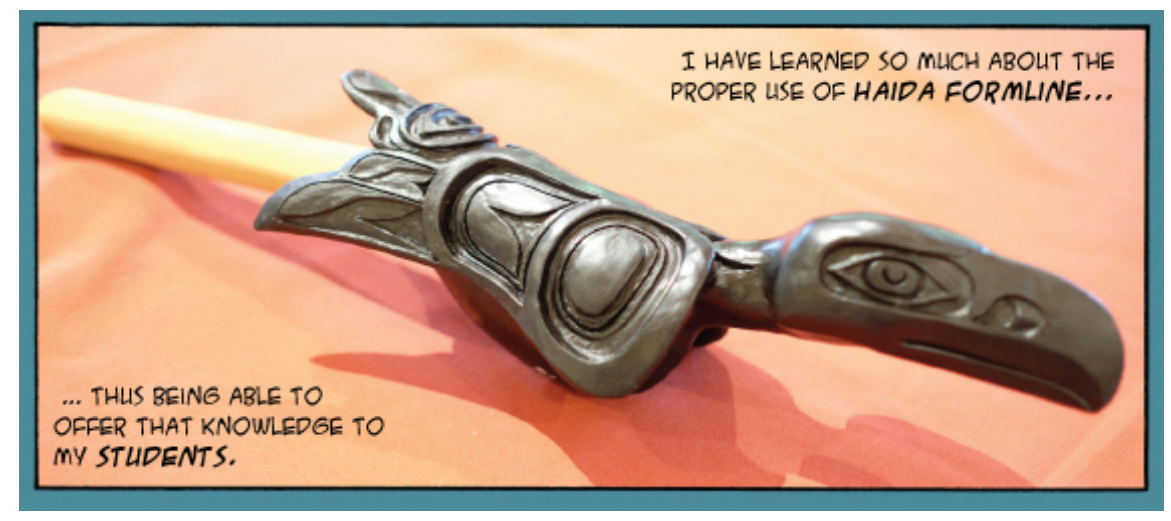

Fig. 7: An example of Kyle's artwork included in the comic.

3. Replotting or re-storying. The comics process is not linear, but rather cyclical. As a "cycle of provocation," Ching describes it as a snowball that generates more detail (and interest) as it moves along. In her opinion, it is a process of replotting or re-storying in order for the researchers to maintain the authenticity of the participants' narrative. In some instances, the process of replotting or re-storying was a requirement due to some of the challenges that research brings forth (i.e., ethics, time constraints, requests for anonymity). Bringing together the various needs of the province and the partnership development grant, called for some creative decisions to be made, one of which being the comic form itself because it facilitated connections between researchers and teachers, and between the ministry and the academy. Furthermore, the use of bright colors, pleasing layouts, and character designs were intentional decisions made on the part of the research team so as to draw teachers (who have hectic schedules) into the narrative and feel a connection with the characters in the story.

The comic in final form, however, represents a significant amount of time in a short number of pages. In order to reduce the "real time" of the story, the researchers had to interpret and synthesize the data into a compelling story. In coming together at multiple stages during the process, they had to exercise judgment and make careful decisions as they worked to refine the comic. Sometimes this was achieved through extracting further elements or details from the fullness of the participants' lived experiences; other times, it involved trying various pictorial strategies to decide if they had been rendered appropriately.

Strategies such as juxtaposition, sequencing, and transitions are tested at different stages of the process so that the research team can experiment with different results. In some instances, Ching will revisit the 
original transcript after the first draft of the comic has been completed in order to judge whether it has achieved the same atmospheric qualities as the teacher's original narrative, or if the avatar has captured the likeness of the teacher's character. In the final stages of the process, the researchers analyze the comic, ensuring that the key elements are told in an evocative, and not necessarily chronological, manner. This is shaped in collaboration while remaining attentive to the teacher's voice. The result is a delicate balance of the participating teacher's voice and the researchers involved in the project.

Replotting, or re-storying, also pertains to how elements of the story affect how the comic is interpreted by the audience who is viewing it or reading it. Both Katrina and Kyle's comics use metaphor, provoking multiple openings where understandings can emerge and shift, a contiguous movement (Irwin \& Springgay, 2008) that may invite the audience to imagine what is occurring in the spaces between each frame or to construct a larger image of what is happening beyond the narrative shared. For some, this may ask that they reflect on their own experiences in teaching and learning, thereby engaging with the comic in a relational way. In this manner, the comic becomes an invitation for the audience to learn about other teachers' mentoring narratives-a platform for storying the experiences of beginning teachers-while also offering a new way of sharing these stories with/in a larger network of teachers.

\section{Rethinking Teacher Stories: Comics \& The Space of Emergence}

A recent study conducted by Clandinin and colleagues (2015) found that early career teacher attrition is an identity-making process that involves complex negotiations between individual and contextual factors. Interviews conducted with 40 second- and third-year teachers in rural, urban, and suburban areas of Alberta, Canada, brought forth the following themes: 1) support, 2) threads of belonging, 3) tensions around contracts, 4) exhaustion, 5) balancing life and career, 6) the struggle to not allow teaching to consume their lives, 7) and other various uncertainties.

Their study prompted questions about how beginning teachers might be sustained by considering each person's storied life instead of solely focusing on individual and/or contextual factors for explaining the reason(s) why teachers leave the practice so early in their career. By shifting focus to the lives of beginning teachers in a more holistic way, Clandinin et al. (2015) encourage researchers to think narratively in order to recognize how teachers are living and composing their lives inside and outside of the school in which they are teaching. In their opinion, this stance demands for an exploration of the role that place, temporality, and personal/social considerations play in teachers' everyday lives in order to identify the reasons why teachers begin to, in Clandinin's (2015) words, "story themselves out of teaching" (p. 13, italics added for emphasis).

At the end of the article, the authors suggest that relational spaces-spaces that foster a continuous re/construction of experience for teachers to help re/compose their lives as they begin to teach—can help better sustain teachers in practice. This paper adds to the premise that relational spaces for reflection and reflexivity can help sustain beginner teachers and we invite others to explore the possibility of doing so through comics because it pays careful consideration to beginning teachers' "storied lives" (Clandinin et al., 2015). 
As Bain, Young, and Kuster (2017) demonstrate, mentoring, like teaching, is not static. Although it sometimes relies on more experienced teachers guiding the development of novice teachers in personal ways, it also requires that teachers involved make judgments and choices to discover the right type of advice or mentoring method for them. This study attests to the emergent and reciprocal nature of mentoring, and it bears witness to how beginning teachers grow in their teaching practices through mentoring. It is our intention to contribute to the critical role in training of teachers and to pay homage to the dynamic interchange (Orland-Barack \& Klein, 2005) that the mentorship process entails. The comic, as an evolution of multiple voices, is an attempt at capturing the complexity of this endeavor and the need for teacher mentorship as a means of providing opportunities for closer teacher relationships, as well as interpersonal and cross-provincial connections.

Emergence is an important concept as it refers to the process of coming into view, or existence. This is in contrast to a static or fixed notion, and in this instance, the comics explored in this paper underscore the proposition of emergence. Theoretically, a "space of emergence" (Osberg \& Biesta, 2008) is where there is no predetermined end point, except to inquire into notions of interest. For the research team, this meant inquiring into how new teachers were learning through adopting a dialogical, collaborative, and relational practice in order to inquire about ways in which new teachers became more effective/reflexive practitioners. The concept of emergence is a process where properties that have never existed before, and sometimes are even inconceivable, are created or somehow come into being. Osberg, Biesta, and Cilliers (2008) define it as a quest for knowledge that is not based on developing "more accurate understandings of a finished reality as it is. Rather, the question for knowledge is more and more complex and creative ways of interacting with our reality" (p. 215). In other words, it is not about fitting into a structure of knowledge that already exists, but rather creating knowledge through an experience of emergence. As new teachers engage with their learning environments, they may come to new understandings. As they construct knowledge through their encounters with their peers, their environments, and through participatory actions (Osberg \& Biesta, 2008), they take the time to become actively engaged with their own processes of learning.

Comics have provided the research team with rich ways to collect, analyze, and share our research. As a collaborative and multimodal assemblage, they have created a platform for the mentors and mentees' voices to be heard and exchanged, while generating new conversations in their evocative character. Therefore, the concept of "emergence" has two layers: one denotes the dynamic process of the research team, while the other makes reference to the rhizomatic connections that the use of comics in the teacher mentoring initiative has made possible. 


\section{Post Comic Dialogues: Comics as a Catalyst for Pedagogical Exchange}

In post-comic conversations, research participants, teachers in the province, and other readers/viewers who were a part of this project, allowed for ongoing analysis of our research findings. In one informal interview, a comic reader revealed the following,

I think that it's a really validating bit of information, to think what this program can make a difference for people and for teachers who are not particularly certain that they can continue in this job. (Laura, personal communication, July 2016)

In another conversation, a comic reader explained,

I think it's neat to witness how comics can harness the power of the narrative. Through this sort of mosaic of comics, we have seen a rich collection of various teacher narratives that highlight the diversity of our province, as well as lived experiences in the teaching profession. (Devon, personal communication, July 2016)

Each comic, unfolding from new teacher experiences in different environments, created a platform for thinking and imagining other supports that can be put in place for new teachers in their practice. Comics have not only become an effective way of telling these stories, but through engaging in comics creation as an artful blend of narrative and arts-based research, our research emphasizes difference by incorporating the lived experiences of people in place, and people in relation to place, which, in turn, can enable further explorations as to how comics-based research can generate multiple and diverse voices.

\section{Conclusion}

In this research project, the creation of comics provided the research team with a rich way to collect, analyze, and share our research. Both Katrina and Kyle's stories, presented in this paper, focus on relations made in remote communities in British Columbia, inspiring other new teachers in similar situations to participate in this study. Both comics have not just become an end product, but a provocation to engender deeper reflection among other teachers who have read their stories and who are participating in the mentoring project, demonstrating how comics, as a mode of arts-based research, offers a new way of mobilizing research knowledge while remaining open to the space of emergence. 


\section{Acknowledgments}

We thank our colleagues, Dr. Ching-Chiu Lin, Julian Lawrence, and Amber Lum, who provided insight and expertise that greatly assisted this research.

This research was funded by the Social Sciences and Humanities Research Council (SSHRC) Canada for Partnership Development Grant entitled, Pedagogical Assemblage: Building and Sustaining Teacher Capacity through Mentoring Programs in British Columbia. This three-year research project is a BC-focused research project on mentorship. It brings together the aligned interests of the Teacher Education Office (TEO) at the University of British Columbia (UBC), the British Columbia Ministry of Education, the British Columbia School Superintendents' Association (BCSSA), and the British Columbia Teachers' Federation (BCTF) to establish a leadership network focused on creating strategies and policies to support and strengthen new teacher practice. This project worked alongside the New Teacher Mentoring Project (NTMP) to study mentorship programs and the ways teacher mentorship grow leadership capacity and mobilize teacher knowledge. The resulting research provides a greater understanding of how to build and sustain teacher capacity through mentoring programs, and subsequently to inform the development of province-wide teacher mentoring programs in British Columbia.

\section{Note}

1. A collection of videos made for this initiative can be viewed on our website: http://mentoringbc.edcp.educ.ubc.ca/research/videos/

\section{References}

Adams, J. (2001). A critical study of comics. The International Journal of Art \& Design Education, 20(2), $133-143$.

Bain, C., Young, J., \& Kuster, D. (2017). Finding the right fit: Three art teachers discover their mentorship style. Art Education, 70(3), 29-33.

Clandinin, D. J., Long, J., Schaefer, L., Downey, C. A., Steeves, P., Pinnegar, E., et al.(2015). Early career teacher attrition: Intentions of teachers beginning. Teaching Education, 26(1), 1-16.

Connelly, F. M., \& Clandinin, D. J. (1990). Stories of experience and narrative inquiry. Educational Researcher, 19(5), 2-14.

Feiman-Nemser, S. (2012). Teachers as learners. Cambridge, MA: Harvard Education Press.

Harvey, M.R., Mishler, E. G., Koenan, K., \& Harney, P.A. (2000). In the aftermath of sexual abuse: Making and remaking meaning in narratives of trauma and recovery. Narrative Inquiry, 10(2), 291-311.

Hong, J. Y. (2010). Pre-service and beginning teachers' professional identity and its relation to dropping out of the profession. Teaching and Teacher Education, 26(8), 1530-1543. 
Ingersoll, R., \& Strong, M. (2011). The impact of induction and mentoring programs for beginning teachers: A critical review of the research. Review of Education Research, 81(2), 201-233.

Irwin, R. L., Lin, C. C., \& Lawrence, J. A. (2015). Mentorship confidential. Teacher Newsmagazine, 27(5), 8-9.

Irwin, R. L., \& Springgay, S. (2008). A/r/tography as practice-based research. In S. Springgay, R. L. Irwin, C. Leggo, \& P. Gouzouasis (Eds.), Being with a/r/tography (pp. xix-xxxiii). Rotterdam, The Netherlands: Sense Publishers.

Jones, S., \& Woglom, J. F. (2013a). Graphica comic arts-based educational research. Harvard Educational Review, 83(1), 168-274.

Jones, S., \& Woglom, J. F. (2013b). Teaching bodies in place. Teachers College Record, 115(8), 1-29.

Karsenti, T. \& Collin, S. (2013). Why are new teachers leaving the profession? Results from a Canadawide survey, Education, 3(3), 141-149.

Kelly, L. M. (2004). Why induction matters. Journal of Teacher Education, 55(5), 438-448.

Kent, A., Feldman, P., \& Hayes, R. (2009). Mentoring and inducting new teachers into the profession: An innovative approach. International Journal of Applied Education Studies, 5(1) 73-95.

Kutsyuruba, J. (2012). Teacher induction and mentorship policies: The pan-Canadian overview. International Journal of Mentoring and Coaching in Education, 1(3), 235-256.

Kuttner, P. J., Sousanis, N., \& Weaver-Hightower, M. B. (2017). How to draw comics in the scholarly way. In P. Leavy (Ed.), Handbook of arts-based research (pp. 396-422). New York, NY: Guilford Press.

Lawrence, J., Lin, C. C., \& Irwin, R. L. (2017). Images, speech balloons, and artful representation: Comics as visual narratives of early career teachers. SANE journal: Sequential Art Narrative in Education, 2(2), Article 3. Retrieved from http://digitalcommons.unl.edu/sane/vol2/iss2/3

Leavy, P. (2009). Method meets art: Arts based research practice. New York, NY: Guilford.

Lin, C.C., Lawrence, J., \& Irwin, R. L. (2016). Changing notions of teacher mentorship in British Columbia. The Canadian Association of Principals Journal. Fall issue, 44-47. Retrieved from http://cdnprincipals.org/blog/category/cap-journal/

Madrid-Manrique, M. (2014). Creating audiovisual participatory narratives: A/r/tography and inclusivity. Unpublished doctoral dissertation, Granada, Spain: University of Granada. Retrieved from https://issuu.com/martamm

Moir, E. (2009). Accelerating teacher effectiveness: Lessons learned from two decades of new teacher induction. Kappan, 91(2), 14-19.

Orland-Barak, L., \& Klein, S. (2005). The expressed and the realized: Mentor's representations of a mentoring conversation and its realization in practice. Teacher and Teacher Education, 21(4), 379-402.

Osberg, D., \& Biesta, G. (2008). The emergent curriculum: Navigating a complex course between unguided learning and planned enculturation. Journal of Curriculum Studies, 40(3), 313-328.

Osberg, D., Biesta, G., \& Cilliers, P. (2008). From representation to emergence. Complexity's challenge to the epistemology of schooling. Educational Philosophy and Theory, 40(1), 213-227. 
Sousanis, N. (2015). Behind the scenes of a dissertation in comics form. Digital Humanities Quarterly, 9(4). Retrieved from http://www.digitalhumanities.org/dhq/vol/9/4/000234/000234.html

Sousanis, N. (2017). Thinking in comics. In M. Cahnmann-Taylor \& R. Siegesmund (Eds.), Arts-based research in education: Foundations for practice (2nd ed., pp. 190-199). Routledge.

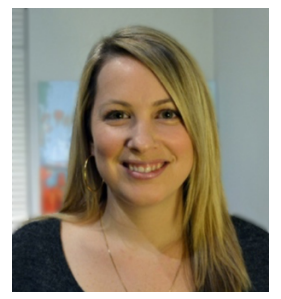

Natalie LeBlanc is a Postdoctoral Research Fellow at the University of British Columbia, where she recently completed her PhD in Curriculum Studies, specializing in Art Education. Natalie has taught a wide range of art and media in a variety of cultural and educational settings in addition to teaching generalist and visual art specialist educators in UBC's post-baccalaureate program. Her research is led by her artistic practice and her work is concerned with examining the pedagogical potential of contemporary art and the intersections between art-making, research, philosophy, and teaching.

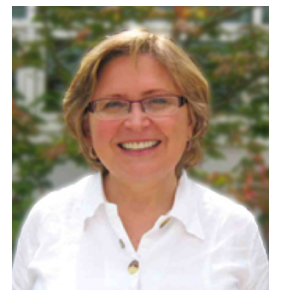

Rita L. Irwin is an artist, researcher, and teacher deeply committed to the arts and education. She is Professor of Art Education in the Department of Curriculum and Pedagogy at the University of British Columbia, Vancouver, Canada and has been an educational leader for a number of provincial, national, and international organizations. While Rita's research interests include arts teacher education, artist-in-residence programs, and sociocultural issues, she is best known for her work in expanding how we might imagine and conduct arts practice-based research methodologies through collaborative and community-based collectives. 
Natalie LeBlanc and Rita L. Irwin

240 | LEARNing Landscapes | Spring 2018, Vol. 11 No. 2 